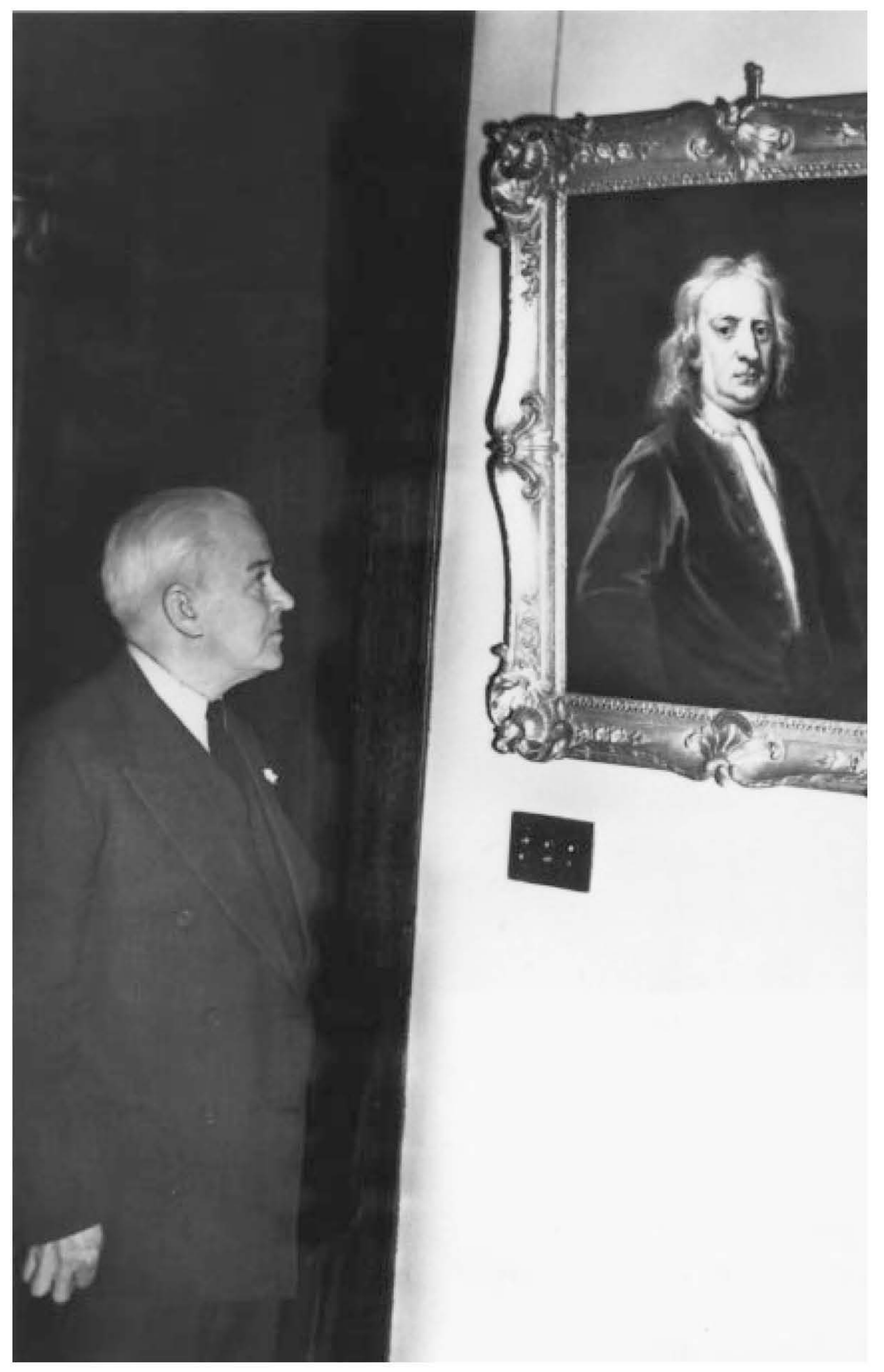


He also has been accused of male chauvinism, anti-Semitism, mistreating his graduate students, and, worst of all, scientific fraud.

\section{In Defense of Robert Andrews Millikan}

by David Goodstein

Isaac Newton (framed) and

Robert Millikan: colleagues

in crime? Speaking of crime, the Newton portrait was stolen from Goodstein's office in 1979.

(Photo courtesy of Don Downie, Pasadena Star-News.)

PICTURE CREDITS: 32, 34-35, 37 - Caltech Archives; 36 American Scientist; 39 - Bob Paz
Robert Andrews Millikan was the founder, first leader, first Nobel Prize winner and all-around patron saint of the California Institute of Technology, an institution that has given me employment for more years than I care to remember. He also has been accused of male chauvinism, antiSemitism, mistreating his graduate students, and, worst of all, scientific fraud. Since we at Caltech feel a solemn duty to defend our hero, my purpose here is to tell his story, look into these various accusations, and, to the extent that I can, mount a defense for Professor Millikan.

Millikan was born in 1868, son of a Midwestern minister. He attended Oberlin College, got his $\mathrm{PhD}$ in physics from Columbia University, did some postdoctoral work in Germany, and, in the last decade of the 19th century, took a position at the brand-new University of Chicago in a physics department headed by his idol, A. A. Michelson.

During the next decade, Millikan wrote some very successful textbooks, but he made little progress as a research scientist. This was a period of crucial change in the history of physics. J. J. Thomson discovered the electron, Max Planck kicked off the quantum revolution, Albert Einstein produced his theories of relativity and the photoelectric effect, and Jean Perrin's experiments and Einstein's theory on Brownian motion established forever that matter was made of atoms. Millikan made no contribution to these events. Nearing 40 years of age, he became very anxious indeed to make his mark in the world of physics. He chose to try to measure the charge of the electron.

Cathode-ray tubes had been around for decades when, in 1896, Thomson in England succeeded in showing that all cathode rays are electrically charged and have the same ratio of electric charge to mass. This was the discovery of the electron. It was the first demonstration that atoms had internal parts. The challenge then was to measure separately the electric charge of the electron.
Thomson and his colleagues tried to do it by observing how an applied electric field changed the rate of gravitational fall of clouds of water droplets that had nucleated on ions in a cloud chamber. The upper edge of the cloud, which had the smallest droplets, could be assumed to contain single charges. In this way, a crude but correct estimate of the unit of electric charge could be obtained. These cloud-chamber experiments were the starting point of Millikan's efforts.

Working with a graduate student named Louis Begeman, Millikan had the idea of applying a much stronger electric field than had previously been used, in the hope of stopping the descent of the cloud completely. To Millikan's surprise, what happened instead was that nearly all of the droplets with their different positive and negative charges dispersed, leaving in view just a few individual droplets that had just the right charge to permit the electric force to come close to balancing the effect of gravity. Millikan quickly realized that measuring the charge on individual ionized droplets was a method far superior to finding the average charge on droplets in a cloud.

It may have been during this period that Millikan's wife, Greta, attending a social event while Millikan spent one of his many long evenings in the lab, was asked where Robert was, according to unpublished remarks by Earnest C. Watson (in the Caltech Archives' Watson papers). "Oh," she answered, "He's probably gone to watch an ion." "Well," one of the faculty wives was later overheard to say, "I know we don't pay our assistant professors very much, but I didn't think they had to wash and iron!"

Unfortunately the single-droplet method had a serious flaw. The water evaporated too rapidly to allow accurate measurements. Millikan, Begeman and a new graduate student named Harvey Fletcher discussed the situation and decided to try to do the experiment with some substance that evaporated more slowly than water. Millikan 


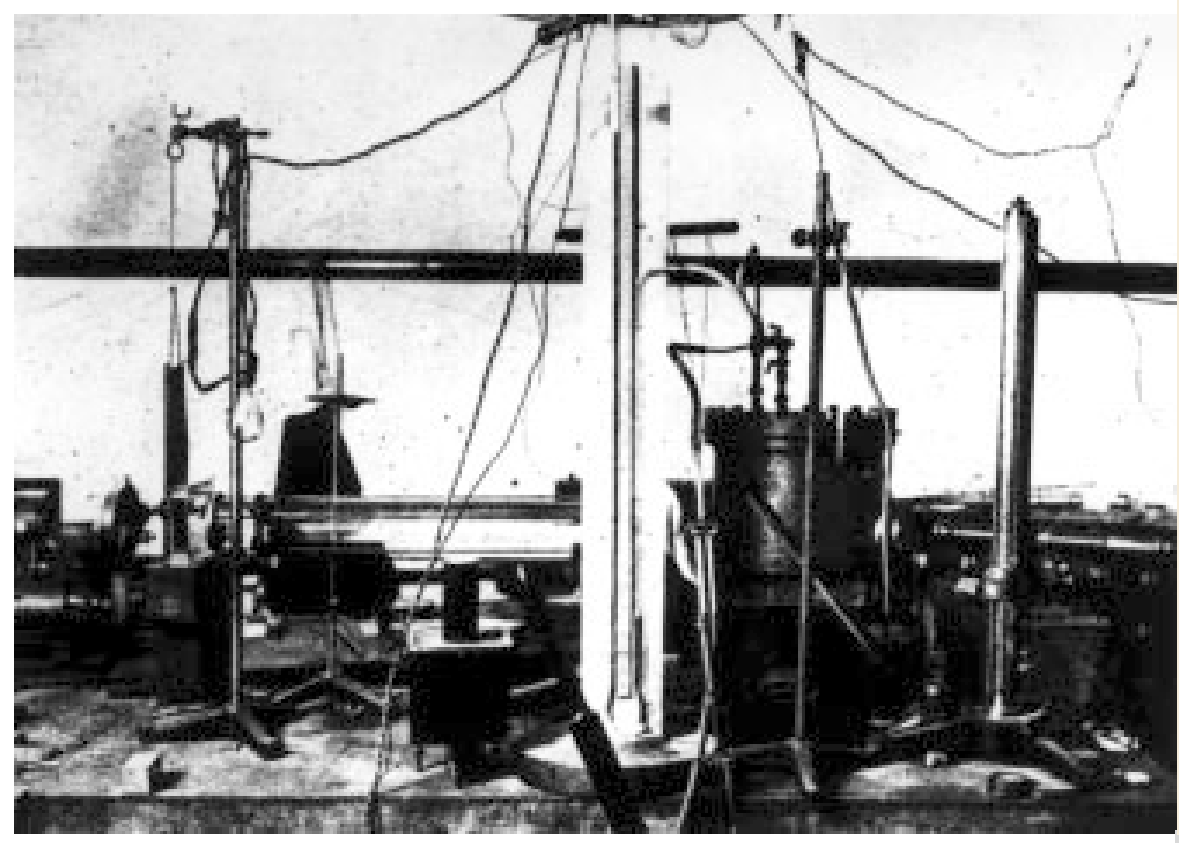

Millikan's oil-drop apparatus, shown above in his Chicago laboratory, had many components, including the hefty brass chamber (at right, set up for a much later demonstration in 1969). A diagram taken from his controversial 1913 paper (bottom right) shows that the chamber contained two metal plates ( $M$ and $N$ ) to which he applied a high voltage, generated by a bank of batteries (B). Fine droplets of oil produced by a perfume atomizer $(A)$ were fed into the top of the chamber. A tiny hole in the upper plate allowed the occasional droplet ( $p$ ) to fall through, at which point it was illuminated by an arc lamp (a) and could be seen in magnification through a telescope. A manometer $(m)$ indicated internal pressure. To eliminate differences in temperature (and associated convection currents), Millikan immersed the brass chamber in a container of motor oil (G), and he screened out the infrared components of the illumination using an $80-\mathrm{cm}$ long glass vessel filled with water $(w)$ and another glass cell filled with a cupric chloride solution (d). An x-ray tube (X) allowed him to ionize the air around the droplet. With this equipment, Millikan could watch an oil drop that carried a small amount of charge rise when the applied electric field forced it upward and fall when only gravity tugged on it. By repeatedly timing the rate of rise and fall, he could determine precisely the electric
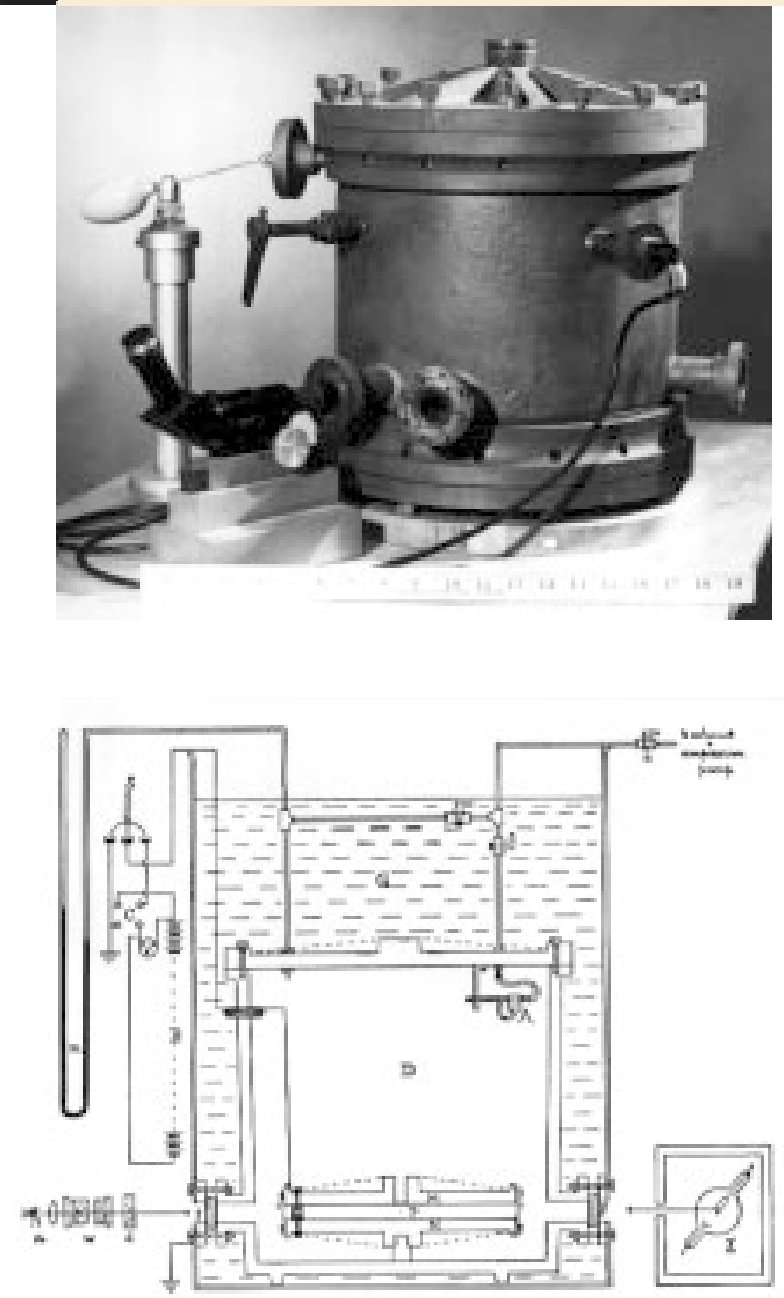
charge on the drop. 
Millikan proposed that Fletcher be sole author on the Brownian motion work and that he, Millikan, be

sole author on the unit-electric-charge work. This is the source of the assertion that Millikan mistreated

his graduate students. No doubt Millikan understood that the measurement of $e$ would establish his

reputation, and he wanted the credit for himself.

assigned to Fletcher the job of devising a way to do the experiment using mercury or glycerin or oil.

Fletcher immediately got a crude apparatus working, using tiny droplets of watch oil made with a perfume atomizer he had bought in a drugstore. He could view the droplets inside the experimental chamber by illuminating them with a bright light and focusing a specially designed telescope on them. Through the eyepiece, he could see the oil droplets dancing around in what is called Brownian motion, caused by impacts of unseen air molecules. This itself was a phenomenon of considerable current scientific interest. When Fletcher got the busy Millikan to look through his telescope at the dancing suspended droplets of oil, Millikan immediately dropped all work on water, and turned his attention to refining the oil-drop method.

A couple of years later (around 1910) Fletcher and Millikan had produced two results. One was an accurate determination of the unit electric charge (called $e$ ) from observing the rate of fall or rise of oil drops in gravitational and electric fields, and the other was a determination of the product $\mathrm{Ne}$, where $N$ is a separate constant called Avagadro's number. The product $N e$ came out of observations of Brownian motion. Millikan approached his student Fletcher with a deal. The academic rules of the time allowed Fletcher to use a published paper as his $\mathrm{PhD}$ thesis, but only if he was sole author. Millikan proposed that Fletcher be sole author on the Brownian-motion work and that he, Millikan, be sole author on the unitelectric-charge work. This is the source of the assertion that Millikan mistreated his graduate students. No doubt Millikan understood that the measurement of $e$ would establish his reputation, and he wanted the credit for himself. Fletcher understood this too, and he was somewhat disappointed, but Millikan had been his protector and champion throughout his graduate career, and so he had little choice but to accept the deal. The two men remained good friends throughout their lives, and Fletcher saw to it that this version of the story was not published until after Millikan's death and his own.

Let us turn now to the question of scientific fraud. In 1984, Sigma Xi published a booklet called Honor in Science. More than a quarter of a million copies were distributed before it was replaced recently by a newer version. Honor in Science includes a brief discussion of the Millikan case that begins, "One of the best-known cases of cooking is that of physicist Robert A. Millikan." Cooking, meaning "retaining only those results that fit the theory and discarding others," is one of the classic forms of scientific misconduct, first described in an 1830 book by Charles Babbage (Reflections on the Decline of Science in England: and its Causes). According to Honor in Science, it is a wellestablished fact that Millikan cooked his data. What is going on here? There are really two stories. One concerns the question of what actually happened back in the period 1910-1917, and the other illustrates how, much more recently, he came to be accused, tried, and convicted of scientific fraud. It's time to tell both of these stories.

The accusation against Millikan, very briefly, is this. After the 1910 paper (with Millikan alone, not Fletcher, as author) presenting his measurement of the unit of electric charge, Millikan found himself embroiled in controversy with the Viennese physicist Felix Ehrenhaft. Ehrenhaft, using a similar apparatus, found cases of electric charges much smaller than Millikan's value of $e$ (Millikan refers to these as "subelectrons"). In order to refute Ehrenhaft's assertion of the existence of subelectrons, Millikan (now working alone; Fletcher had received his doctorate and left) made a new series of measurements, published in 1913, in which the charge on every single droplet studied was, within a very narrow range of error, an integer multiple of a single value of $e$. The 1913 paper succeeded in dispatching Ehrenhaft, and 


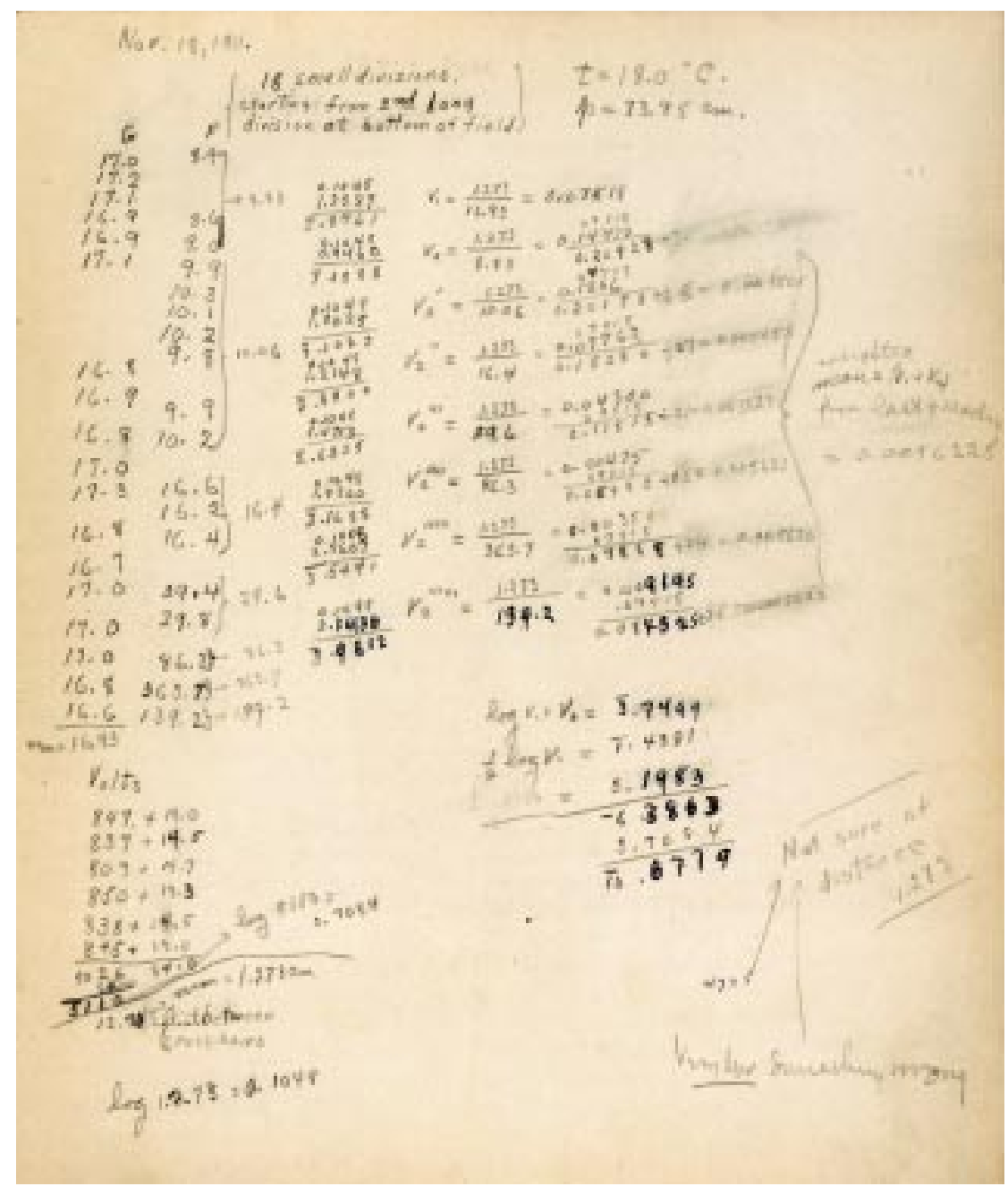

Millikan's lab notebooks provide some insight into

his methods. The page

above, dated November I8,

I9II, shows his observa-

tions at left under $G$, for

gravity, and F, for field, and

his calculations to the

right. This drop and the

ones for which comments

are excerpted at top right,

were not among those

included in Millikan's

published paper. The

experiment dated March

14, 1912 (opposite page),

with its exuberant red

notation, was indeed

published. contributed significantly to Millikan's 1923 Nobel Prize. An examination, however, of Millikan's private laboratory notebooks (housed in the Caltech Archives) reveals that he did not in fact report every droplet on which he recorded data. He reports the results of measurements on 58 drops, whereas the notebooks reveal data on approximately 175 drops in the period between November 11, 1911, and April 16, 1912. In a classic case of cooking, the accusation goes, he reported results that supported his own hypothesis of a smallest unit of charge, and discarded those contrary results that would have supported Ehrenhaft's position. And, to make matters very much worse, he lied about it. The 1913 paper presenting Millikan's results contains this explicit assertion: "It is to be remarked, too, that this is not a selected group of drops, but represents all the drops experimented upon during 60 consecutive days, during which time the apparatus was taken down several times and set up anew." (Emphasis in the original.) Thus, Millikan is accused of cheating and then compounding his cheating by lying about it in one of the most important scientific papers of the 20th century. There couldn't be a clearer case of scientific misconduct.

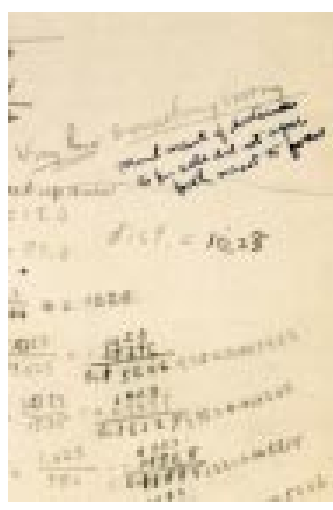

Let us look at some of the pages in Millikan's private laboratory notebooks. The one at left is dated November 18, 1911. At the top right the temperature is noted as $\mathrm{t}=18.0^{\circ} \mathrm{C}$ (obviously, Millikan's lab was not well heated for the bitter Chicago weather) and the pressure, $73.45 \mathrm{~cm}$ (possibly a stormy day). On the left, we see a column of figures under $G$, for gravity. These were the times taken for a tiny droplet-a pinpoint of light, too small to focus in his telescopeto fall between scratch marks in the telescope's focal plane. These measurements gave the terminal velocity of the drop when the force of gravity was balanced by the viscosity of air. From this measurement alone, he could determine the size of the tiny, spherical drop.

Then there is another column under $F$ for field. These were the times taken for the drop to rise between the scratch marks under the combined influence of gravity, viscosity, and the applied electric field, which had been turned off during the $G$ measurements. The combined $F$ and $G$ measurements made it possible to determine the charge on the drop. We can see that the $F$ measurements change from time to time. The first series give an average of 8.83 , then 10.06 , then 16.4 , and so on. That happens because the charge on the drop changes from time to time, when the drop captures an ion from the air. Millikan made use of the changes to help deduce the number of units of charge on the drop.

To the right of these columns appears a series of laborious hand calculations (not necessarily done on the same day that the data were taken), using logarithms to do multiplication and square roots, and then finally, bottom right, the comment, "very low something wrong" with arrows to "not sure of distance." Needless to say, this was not one of the 58 drops Millikan published.

Another page shows observations on two drops, taken November 20 and 22, 1911, with similar columns of figures (excerpt above). To the right at 
the bottom of the first observation we see again "very low something wrong" and below that, "found meas[uremen]t of distance to the hole did not. ..." Once again, not up to snuff. But on a page dated December 20, 1911 (the temperature now a comfortable $22.2^{\circ} \mathrm{C}$-did the university turn the heat on in December?), we find the remark: "This is almost exactly right $\&$ the best one I ever had!!!” (left).

Millikan, in his crucial 1913 paper, did not publish any of the drops for which the raw data are shown in these three pages, not even "the best one I ever had." This was all part of a warm-up period during which Millikan gradually refined his apparatus and technique in order to make the best measurements anyone had ever made of the unit of electric charge. The first observation that passed muster and made it into print was taken on February 13,1912 , and all of the published data were taken between then and April 16, 1912, actually a period of 63 days (1912 was a leap year). Raw data taken during this period are shown in the notebook page below, dated March 14, 1912. Our eye is immediately drawn to the comment, on the top center part of the page, "Beauty Publish."

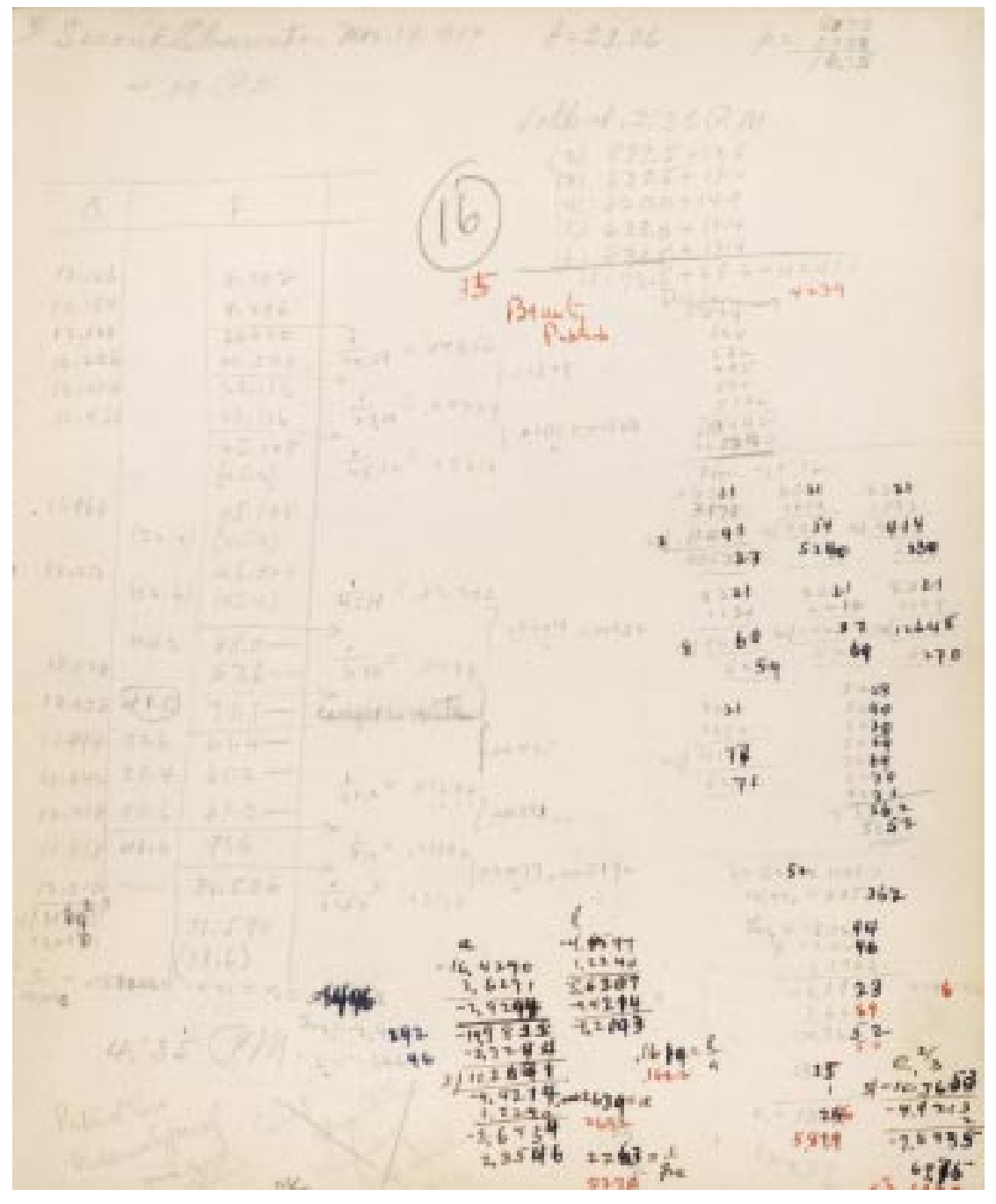

Note also the pressure, $16.75 \mathrm{~cm}$-too low for even the stormiest day in Chicago.

During these 63 days, Millikan recorded in his notebooks data for about 100 separate drops. Of these, about 25 are obviously aborted during the run, and so cannot be counted as complete data sets. Of the remaining 75 or so, he chose 58 for publication. Millikan's standards for acceptability were exacting. If a drop was too small, it was excessively affected by Brownian motion, or at least by inaccuracy in Stokes's law for the viscous force of air (more about this later). If it was too large, it would fall too rapidly for accurate measurement. He also preferred to have a drop change its charge a number of times in the course of an observation, so that he could have changes in charge, as well as a total charge, which had to be integer multiples of a single unit of charge. None of this could be determined without actually taking and recording data on a candidate drop. Thus, it should not be surprising that Millikan chose to use the data on only 58 of the drops he observed during the period when he and his apparatus had reached near perfection. Furthermore, he had no special bias in choosing which drops to discard. A modern reanalysis of Millikan's raw data by Allan Franklin (see following page) reveals that his result for the unit of charge and for the limits of uncertainty in the result would barely have changed at all had he made use of all the data he had, rather than just the 58 drops he used.

I don't think that any scientist, having studied Millikan's techniques and procedures for conducting this most demanding and difficult experiment, would fault him in any way for picking out what he considered to be his most dependable measurements in order to arrive at the most accurate possible result. In the 1913 paper, he cites his result with an uncertainty of 0.2 percent, some 15 times better than the best previous measurement (which reported an error of 3 percent). Furthermore, the value of the charge of the electron today agrees with Millikan's result within his cited uncertainty of 0.2 percent. The experiment was nothing less than a masterpiece, and the 1913 paper reporting it is a classic of scientific exposition. Nevertheless, it contains the phrase "this is not a selected group of drops, but represents all the drops experimented upon during 60 consecutive days," which is manifestly untrue. The question is, why did Millikan mar his masterpiece with a statement that clearly is not true?

Many years after the fact, Millikan's work was studied by historian Gerald Holton, who told the story of the Millikan-Ehrenhaft dispute ("Subelectrons, Presuppositions, and the MillikanEhrenhaft Dispute," in Historical Studies in the Physical Sciences, 1981) and contrasted Millikan's published results with what he found in Millikan's laboratory notebooks. Holton did not accuse Millikan of misconduct of any kind, but instead found in the unpublished laboratory notebooks an 


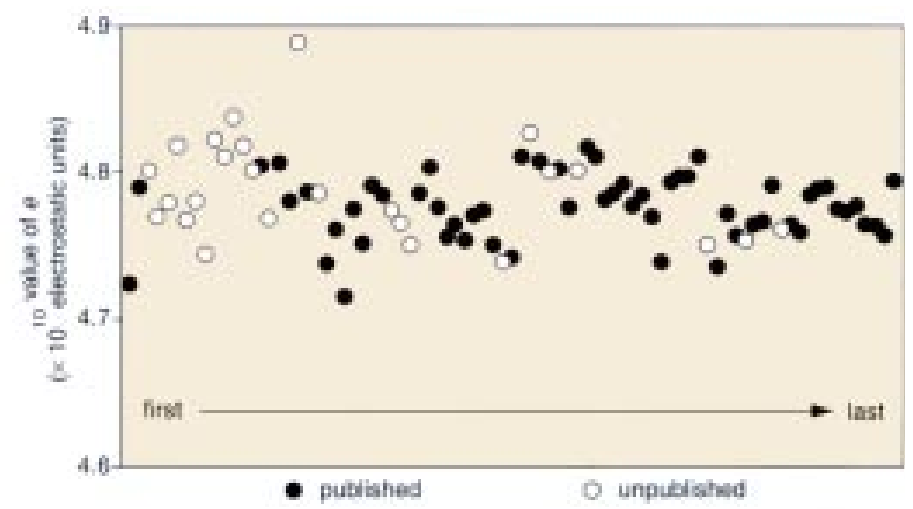

Allan Franklin's reanalysis

of Millikan's observations

on published (solid) and

unpublished (open) oil

drops demonstrates that

the scatter in his results

lessened over time. Shown

here are estimates of $e$

derived from all the drops

for which Millikan obtained

adequate data after

February 13, 1912, the day

he gathered observations

on the first of the $\mathbf{5 8}$

drops he ultimately

published. Millikan was

clearly being selective, but

his choice of drops did not

bias the overall result.

opportunity to contrast a scientist's public, published behavior with what went on in the privacy of the laboratory. Holton's work was seized upon by two journalists, William Broad and Nicholas Wade, who in 1982 published a book about misconduct in science called Betrayers of the Truth. Broad and Wade, both of whom were then reporters for Science magazine, and both of whom now write for the New York Times, are the ones who tried and convicted Robert Millikan of scientific misconduct. Others, like the writer of Sigma Xi's Honor in Science, simply bought their argument at face value.

In Betrayers of the Truth, Broad and Wade want to make the point that scientists cheat. Chapter 2, "Deceit in History," starts out with a list of culprits: Claudius Ptolemy, Galileo Galilei, Isaac Newton, John Dalton, Gregor Mendel, and Robert Millikan. At the very least, Millikan is in good company. Of Millikan they say he "extensively misrepresented his work in order to make his experimental results seem more convincing than was in fact the case."

Every revision of his technique, every improvement of his apparatus, every word he wrote, public or private, was directed toward one goal only: the most accurate possible measurement of the charge of the electron.

I would argue that this statement is profoundly incorrect. (The accusations against most of the other scientists on the list are equally spurioussee "Scientific Fraud," EES, Winter 1991.)

For the statement by Broad and Wade to make sense, Millikan's principal experimental result would have to be that there exists a smallest unit of electric charge. We would have to imagine that the existence of electrons, and by implication, the existence of atoms, was an issue of burning controversy in 1913, with Millikan on one side and Ehrenhaft on the other, and that the whole point of Millikan's exercise was to prove that "subelectrons" did not exist. In fact, there were in 1913 a small number of respectable scientists who still insisted that the existence of unseen atoms was an unnecessary and unscientific hypothesis, but they had by then been left far behind by the mainstream of science, and besides, even they would not have chosen Ehrenhaft as their champion. To Millikan, who had seen Brownian motion with his own eyes, the existence of atoms and electrons was beyond question. Every revision of his technique, every improvement of his apparatus, every word he wrote, public or private, was directed toward one goal only: the most accurate possible measurement of the charge of the electron. Ehrenhaft and the supposed controversy are never so much as mentioned. And it is worth remembering that history has vindicated Millikan in that his result is still regarded as correct. Nevertheless, we are still stuck with the blatantly false statement, " $[A] 11$ the drops experimented upon during 60 consecutive days."

To understand the significance of that statement, I must make a small digression. Millikan's oil drops rose and fell under the influence of three countervailing forces: gravity, electricity, and viscosity. The first two of these were very well understood. For the third, the 19th-century hydrodynamicist George Stokes had produced an exact formula applicable to a sphere moving slowly through an infinite, continuous viscous medium. The conditions that would make Stokes's law exact were well-satisfied by Millikan's oil drops in all respects except one: the drops were so small that the air through which they moved could not safely be considered a continuous medium. Instead, the air was made up of molecules, and the average distance between molecules was not completely negligible compared to the size of an oil drop. For this reason, Stokes's law could not be depended on as absolutely correct.

To deal with this problem, Millikan assumed, entirely without theoretical basis, as he stressed in his paper, that Stokes's law could be adequately corrected by an unknown term that was strictly proportional to the ratio of the distance between air molecules to the size of the drop, so long as that ratio was reasonably small. To test this idea, he purposely made that damaging ratio larger than it had to be by pumping some of the air out of his experimental chamber. That is the reason he recorded such low pressure in the page from his notebook dated March 14, 1912. Then, when he had assembled all of his data, he used a trick that would be appreciated by any experimentalist. He plotted a graph of all his data in such a way that, if his supposition was correct, all the data points would fall on a single straight line, and the posi- 
tion of the line on the graph would give the magnitude of the unknown correction term. Thus, if it were successful, this procedure would all at once prove that the proposed method of correcting Stokes's law was justified, and give the magnitude of the necessary correction. In other words, this procedure, like everything else in this experiment, was designed not to question whether charge came in units, but rather to measure the unit of charge with the greatest possible accuracy.

Now let's turn to Millikan's actual published paper. It begins on page 109 of Volume II, No. 2, of the Physical Review. He explains how the experiment is done and (with specific drops as examples) how he analyzes his data, using changes in the charge on a drop to help determine the total number of units of charge on the drop. Then, on page 133, he writes: "Table XX contains a complete summary of the results obtained on all of the 58 different drops upon which complete series of observations were made during a period of 60 consecutive days." As we have already seen, his published results came from measurements made over a period of 63 , not 60 days, but I think we can forgive him that lapse. The clear implication of the sentence is that there were only 58 drops for which the data were complete enough to be included in the analysis.

Page 133 is followed by two pages of Table XX, and an additional two pages of the graph of the straight-line test of the correction to Stokes's law described above. On page 138, Millikan discusses his test of his presumed correction to Stokes's law. He points out that all of the points do indeed fall on the line, and in fact, "there is but one drop in the 58 whose departure from the line amounts to as much as 0.5 percent." And then, the very next sentence is, "It is to be remarked, too, that this is not a selected group of drops, but represents all the drops experimented upon during 60 consecutive days ..." The damning remark is made, not in regard to whether charge comes in units, but in regard to getting the correction to Stokes's law right. What he means to say is, "Every one of those 58 drops I told you about confirms my presumed formula for correcting Stokes's law." And, although in Physical Review it comes five pages after the remark that qualified the choice of those 58 drops, the intervening pages are tables and graphs. In the typescript submitted by Millikan (which does not survive, to my knowledge) it would have followed almost immediately after the qualifying statement. Thus a careful reading of the context of Millikan's words greatly diminishes their apparent significance as evidence of misconduct.

In fairness, it should be pointed out that, when Millikan published his book The Electron in 1917 , he did take the trouble to confront Ehrenhaft explicitly and to demolish Ehrenhaft's arguments
Cosmic rays were the subject of Millikan's research in the latter half of his career, after coming to Caltech in 1921 at the age of 53. Not only did he give them their name and call attention to their significance, he also lugged detectors such as this one to various altitudes around the world to measure the rays. Millikan died in 1953.

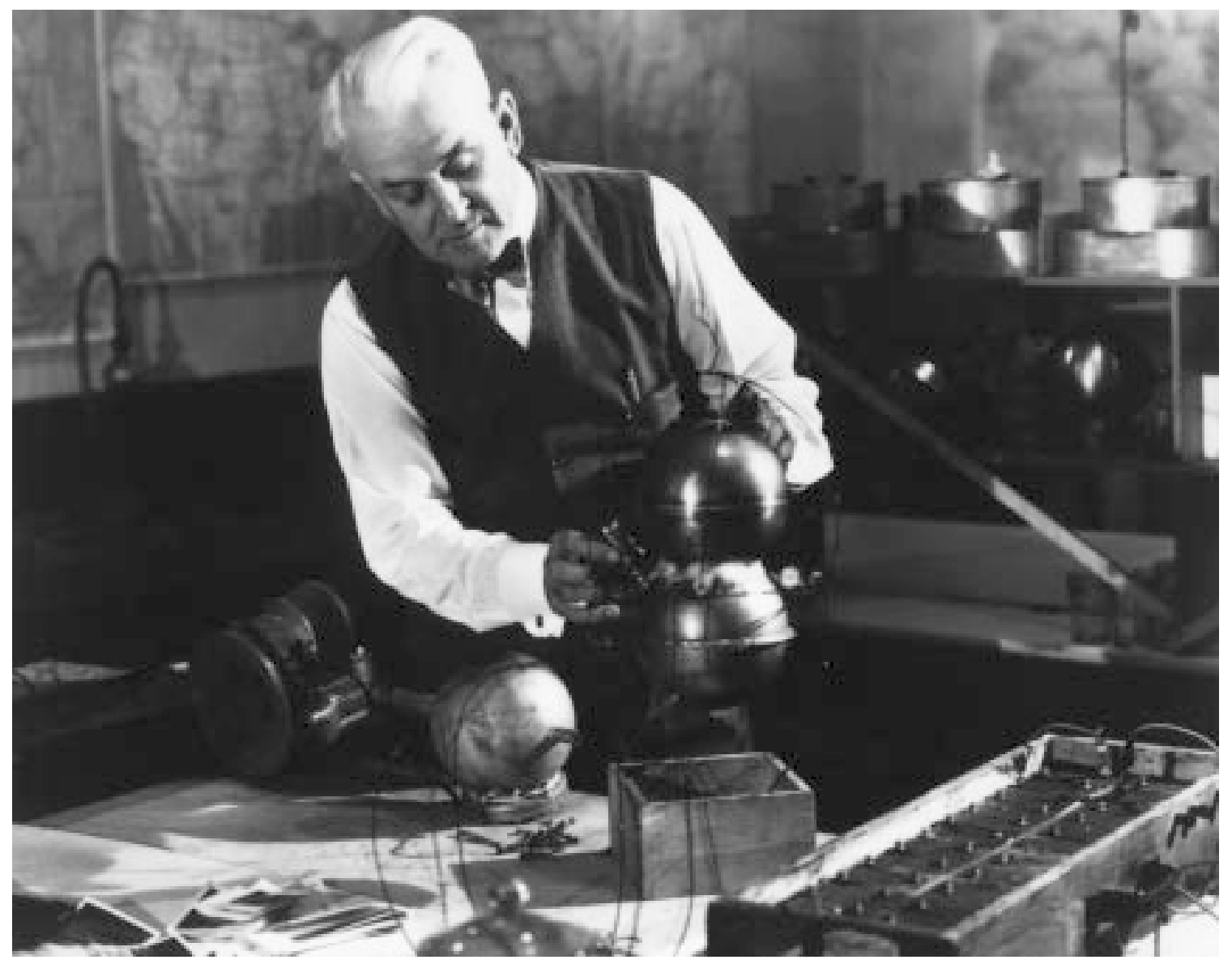


I believe, after reading The Electron, that Millikan's real rival was never the

hapless Ehrenhaft, but rather J. J. Thomson-not because they disagreed scientifically, but because both wanted to be remembered in history as the father of the electron

very effectively. He also used verbatim the section of his 1913 paper on Stokes's law, thus repeating the offending assertion of having used every drop, without the earlier qualifying statement. Most probably by 1917 , he had forgotten the very existence of the other drops he had observed, however incompletely, between February and April of 1912. I believe, after reading The Electron, that Millikan's real rival was never the hapless Ehrenhaft, but rather J. J. Thomson-not because they disagreed scientifically, but because both wanted to be remembered in history as the father of the electron.

In recent times, Millikan has become a juicy target for certain historians because he was very much a part of the establishment, as well as being white and male, and, of course, he is no longer here to defend himself (I'm trying to fill in on that last point). For example, there is a letter, noted in feminist circles, in which Millikan advised the president of Duke University not to hire a female professor of physics. This occurs much later, in 1936, and Millikan is now the famous and powerful head of the California Institute of Technology. W. P. Few, Duke's president, had written to Millikan in confidence, asking his advice on this delicate issue. Millikan's reply shows his unease: "I scarcely know how to reply to your letter. ..." he begins. "Women have done altogether outstanding work and are now in the front rank of scientists in the fields of biology and somewhat in the fields of chemistry and even astronomy," Millikan writes later, "but we have developed in this country as yet no outstanding women physicists." $\mathrm{He}$ points out that "Fräulein Meitner in Berlin and Madame Curie in Paris" are among the world's best physicists, but that's Europe, not the U.S. "I should therefore," he concludes his confidential advice, "expect to go farther in influence and get more for my expenditure if in introducing young blood into the department of physics I picked one or two of the most outstanding younger men, rather than if I filled one of my openings with a woman."

In his private correspondence, Millikan also reveals an attitude toward Jews that would not be acceptable today. For example (as noted in Millikan's School by Judith R. Goodstein), writing from Europe to his wife, Greta, he describes physicist Paul Ehrenfest (not to be confused with Felix Ehrenhaft) as "a Polish or Hungarian Jew [Ehrenfest was, in fact, Austrian] with a very short, stocky figure, broad shoulders and absolutely no neck. His suavity and ingratiating manner are a bit Hebraic (unfortunately) and to be fair, perhaps I ought to say too that his genial open-mindedness, extraordinarily quick perception and air of universal interest are also characteristic of his race."

What are we to make of these lapses? They are certainly not the rantings of a mindless bigot. Undoubtedly Millikan's biases were typical at the time of a man of his upbringing and background. It should be said that, regardless of whatever prejudices he harbored, they never interfered with his judgment of scientists. His hero A. A.

Michelson was Jewish, as were many of the stars Millikan personally recruited to Caltech: Paul Epstein, Albert Einstein, Theodore von Kármán, and Beno Gutenberg among others. Such actions demonstrate that Millikan's personality was more complex than his detractors acknowledge. Like anyone, he had his strengths and his flaws. He wasn't generous enough to put his student's interests ahead of his own at a critical point in his career. In describing the results of his oil-drop experiment, he let himself get carried away a bit in demonstrating the correctness of his empirical correction to Stokes's law. And his words about women and Jews grate on modern sensibilities. But Robert Andrews Millikan was not a villain. And he certainly did not commit scientific fraud in his seminal work on the charge of the electron.

Ladies and gentlemen, the defense rests.

David Goodstein, professor of physics and applied physics, the Frank J. Gilloon Distinguished Teaching and Service Professor, and vice provost, has, he claims, the longest title at Caltech and possibly in all of academia. He has also been a member of the faculty a rather long time, having joined it in 1966 after receiving his $P h D$ from the University of Washington. Although his own research has been in low-temperature physics, Goodstein has been a loyal author for $\mathrm{E} \& \mathrm{~S}$ over the last couple of decades on topics ranging from scientific fraud to superconductivity to the excess supply of $P b D$, as well as contributing numerous book reviews. $\mathrm{E} \& \mathrm{~S}$ hasn't always been the primary recipient, as is the case with this article, which is adapted from an address to the 2000 Sigma Xi Forum, "New Ethical Challenges in Science and Technology," in November, where he received Sigma Xi's John P. McGovern Science and Society Award. The lecture was first published in the January-February 2001 issue of American Scientist. 